\title{
Negative Ion-Atmospheric Pressure Photoionization-Mass Spectrometry
}

\author{
Tiina J. Kauppila, Tapio Kotiaho, and Risto Kostiainen* \\ Viikki Drug Discovery Technology Center, Department of Pharmacy, University of Helsinki, Helsinki, Finland
}

\author{
Andries P. Bruins \\ University Center for Pharmacy, University of Groningen, Groningen, The Netherlands
}

\begin{abstract}
The ionization mechanism in the novel atmospheric pressure photoionization mass spectrometry (APPI-MS) in negative ion mode was studied thoroughly by the analysis of seven compounds in 17 solvent systems. The compounds possessed either gas-phase acidity or positive electron affinity, whereas the solvent systems had different polarities and gas-phase acidities and some of them positive electron affinities. The analytes that possessed gas-phase acidity formed deprotonated ions in proton transfer; in addition, fragments and solvent adducts were observed. The compounds of positive electron affinity formed negative molecular ions by electron capture or charge exchange and substitution products of form $[\mathrm{M}-\mathrm{X}+$ $\mathrm{O}^{-}$by substitution reactions. The efficiency of deprotonation was decreased if the solvent used possessed higher gas-phase acidity than the analyte. Solvents of positive electron affinity captured thermal electrons and deteriorated the ionization of all the analytes. Also, the proportion of substitution products was affected by the solvent. Finally, the performances of negative ion APPI and negative ion APCI were compared. The sensitivity for the studied compounds was better in APPI, but the formation of substitution products was lower in APCI. (J Am Soc Mass Spectrom 2004, 15, 203-211) (C) 2004 American Society for Mass Spectrometry
\end{abstract}

$\mathrm{A}$ tmospheric pressure photoionization (APPI) has recently been introduced as a new ionization method for liquid chromatography-mass spectrometry (LC-MS) [1, 2]. In APPI the liquid sample is vaporized in a heated nebulizer similar to the one in atmospheric pressure chemical ionization (APCI) ion source. Photons emitted by a krypton discharge lamp initiate a series of gas-phase reactions that lead to the ionization of the analyte. Two distinct APPI apparatuses have been described by Robb et al. [1] and Syage et al. [2]. This study concentrates on dopant assisted APPI, developed by Robb et al. [1]. Thus far APPI has been applied to the analysis of flavonoids [3], steroids [4], drugs, and their metabolites [5, 6], naphthalenes [7] and aromatic imines and amines [8].

The ionization process in dopant assisted APPI in positive ion mode is initiated by the photoionization of a dopant (e.g., toluene) and formation of a dopant radical cation $[1,7,9]$. Next, the dopant radical cation can ionize the solvent molecule by proton transfer, if the proton affinity (PA) of the solvent molecule is higher

Published online December 10, 2003

Address reprint requests to Dr. R. Kostiainen, Department of Pharmacy, Division of Pharmaceutical Chemistry, University of Helsinki, P.O. Box 56, FIN-00014, Finland. E-mail: risto.kostiainen@helsinki.fi

*Also affiliated with the Department of Pharmacy, Division of Pharmaceutical Chemistry, University of Helsinki, Helsinki, Finland. than that of the deprotonated radical cation. Protonated solvent molecules can donate a proton to the analyte molecule, in case the PA of the analyte is higher than that of the solvent molecule. Alternatively, the dopant radical cation can ionize the analyte directly by charge exchange, if the ionization energy of the analyte is lower than that of the radical cation. Thus, two routes of ionization are possible in positive ion APPI-charge exchange and proton transfer-the route depends on the ionization energy and proton affinity of the analyte and the solvent. Charge exchange makes ionization of non-polar compounds possible, which may not be possible by using electrospray or APCI.

Preliminary results on negative ion APPI indicated that negative ions can be formed by electron capture, charge exchange, proton transfer, or substitution reactions [7]. The aim of this work is to study in detail the ionization mechanism and solvent effect in negative ion APPI. Thus, seven analytes that possess gas-phase acidity or positive electron affinity (EA) were chosen to enable different ionization mechanisms in negative ion APPI. The compounds were analyzed in 17 solvents that have different polarities and gas-phase acidities; in addition two of them have positive EAs. Also, the effect of operational parameters on formation of substitution products was studied. Finally, a comparison to negative ion APCI was made. 
Table 1. The solvents used in the study

$\begin{array}{ll}\text { 1. } & \text { Hexane } \\ \text { 2. } & \text { Chloroform } \\ \text { 3. Water } \\ \text { 4. Methanol } \\ \text { 5. Acetonitrile } \\ \text { 6. Water/methanol (50/50\%) } \\ \text { 7. Water/ acetonitrile (50/50\%) } \\ \text { 8. Water/ methanol/ acetic acid (50/50/0.1\%) } \\ \text { 9. Water/ methanol/ ammonium acetate }(50 / 50 / 0.1 \%) \\ \text { 10. Water/ methanol/ ammonium hydroxide }(50 / 50 / 0.1 \%) \\ \text { 11. Water/ methanol/ formic acid }(50 / 50 / 0.1 \%) \\ \text { 12. Water/ methanol/ trifluoroacetic acid }(50 / 50 / 0.1 \%) \\ \text { 13. Water/ acetonitrile/ acetic acid }(50 / 50 / 0.1 \%) \\ \text { 14. Water/ acetonitrile/ ammonium acetate }(50 / 50 / 0.1 \%) \\ \text { 15. Water/ acetonitrile/ ammonium hydroxide }(50 / 50 / 0.1 \%) \\ \text { 16. Water/ acetonitrile/ formic acid }(50 / 50 / 0.1 \%) \\ \text { 17. Water/ acetonitrile/ trifluoroacetic acid }(50 / 50 / 0.1 \%)\end{array}$

\section{Experimental}

\section{Reagents}

The solvents used in the study are given in Table 1. The structures of the studied compounds are shown in Figure 1 and thermodynamic data for the solvents and analytes is given in Table 2. 2-Naphthoic acid, 2-naphthol, 3-methyl-2,5-furandione, 2,5-furandione, hexachlorobenzene, 1,4-dinitrobenzene, 1,4-naphthoquinone, and acetone were purchased from Sigma-Aldrich (Steinheim, Germany). 3-Methyl-2,5-furandione and 2,5-furandione were used as supplied (purities $98 \%$ and $>99 \%$, respectively), without purification. Acetonitrile, hexane, chloroform and acetic acid were purchased from Rathburn (Walkerburn, Scotland), toluene from J. T. Baker (Phillipsburg,) and methanol and ammonium hydroxide from J. T. Baker (Deventer, Netherlands). Formic acid was purchased from Riedel-de Haën (Seelze, Germany), trifluoroacetic acid from Fluka (Neu-Ulm, Switzerland) and ammonium acetate from
Table 2. Energies of the solvents and compounds studied

\begin{tabular}{lcc}
\hline Compound & $\mathrm{EA}(\mathrm{eV})$ & $\Delta \mathrm{G}_{\text {acid }}\left(\mathrm{kJ} \mathrm{mol}^{-1}\right)$ \\
\hline \hline Benzyl radical & 0.912 & - \\
$\mathrm{O}_{2}$ & 0.451 & - \\
Hexane & - & - \\
Water & - & 1607 \\
Methanol & - & 1565 \\
Acetonitrile & 0.011 & 1561 \\
Chloroform & 0.622 & 1464 \\
$\mathrm{Cl}$ & 3.6 & - \\
$\mathrm{HCl}$ & - & 1373 \\
$\mathrm{HO}{ }_{2 *}$ & - & 1451 \\
Phenol $_{\text {Acetic acid }}$ & - & 1432 \\
Formic acid & - & 1429 \\
2-Naphthol & - & 1415 \\
$\mathrm{HNO}_{2}$ & - & 1408 \\
NO & & 1396 \\
Benzoic acid & - & - \\
2-Naphthoic acid & 2.273 & 1393 \\
Trifluoroacetic acid & - & $1370^{\mathrm{a}}$ \\
3-Methyl-2,5-furandione & - & 1328 \\
2,5-Furandione & - & - \\
Hexachlorobenzene & 1.297 & - \\
1,4-Dinitrobenzene & 0.915 & - \\
1,4-Naphthoquinone & 2.003 & - \\
\hline
\end{tabular}

aThe gas-phase acidity of 2-naphthoic acid was estimated from the gas-phase acidities of 2-naphthol $\left(1408 \mathrm{~kJ} \mathrm{~mol}^{-1}\right)$, phenol $(1432 \mathrm{~kJ}$ $\left.\mathrm{mol}^{-1}\right)$, and benzoic acid $\left(1393 \mathrm{~kJ} \mathrm{~mol}^{-1}\right)$, see text [10].

Merck (Darmstadt, Germany). All the chemicals were of analytical or chromatographic grade. The water was purified in a Milli-Q water purification system (Millipore, Molsheim, France).

\section{Sample Preparation}

Stock solutions of 1 or $10 \mu \mathrm{mol} / \mathrm{ml}$ were prepared in hexane, chloroform, methanol, and acetonitrile or in case of poor solubility in toluene. The stock solutions

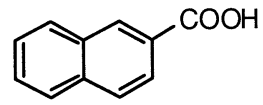

A

2-naphthoic acid

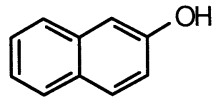

B 2-naphthol

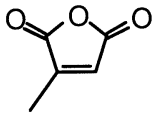

C

3-methyl2,5-furandione

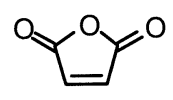

D 2,5-furandione<smiles>Clc1c(Cl)c(Cl)c(Cl)c(Cl)c1Cl</smiles>

E hexachlorobenzene<smiles>O=[N+]([O-])c1ccc([N+](=O)[O-])cc1</smiles>

$F$

1,4-dinitrobenzene<smiles>O=C1C=CC(=O)c2ccccc21</smiles>

G 1,4-naphthoquinone

Figure 1. Structures of the studied compounds. 
were diluted in the studied solvent systems (Table 1) to a final concentration of $10 \mathrm{nmol} / \mathrm{ml}$. Hexachlorobenzene was not studied in water because of its weak solubility.

\section{Instrumentation}

The solvent was delivered from a HP 1100 series binary pump (Hewlett Packard, Waldbronn, Germany) at flow rate of $200 \mu \mathrm{l} / \mathrm{min}$. The $10 \mathrm{nmol} / \mathrm{ml}$ samples were injected into a continuous solvent stream by using a HP 1100 series autosampler (Agilent Technologies, Waldbronn, Germany) and injection volume of $50 \mu \mathrm{l}$. A micro-syringe pump (Harvard Apparatus Inc., Holliston, MA) was used to deliver the dopant at a flow rate of $20 \mu \mathrm{l} / \mathrm{min}$. HPLC-grade toluene was used as the dopant. A PE Sciex API 3000 triple quadrupole mass spectrometer (Sciex, Concord, Canada) utilizing APPI (Machine Shop, University of Groningen, Netherlands) and APCI (Sciex, Toronto, Canada) interfaces was used. The photoionization lamp used was a $10 \mathrm{eV}$ model PKS 100 krypton discharge lamp (Cathodeon Ltd., Cambridge, England). The temperature of the nebulizer was $450{ }^{\circ} \mathrm{C}$. High purity nitrogen $(99.999 \%$, Oy Woikoski Ab, Voikoski, Finland) was used as nebulizer, curtain and lamp gases and high purity nitrogen or compressed air filtered by an Atlas Copco air dryer (Wilrijk, Belgium) was used as auxiliary gas. Data were collected using a Dell OPTIPLEX computer and PE Sciex Analyst software (version 1.1). The instrument was operated in negative ion mode. The APPI source block was $-1300 \mathrm{~V}$ and the declustering potential $20 \mathrm{~V}$. The scan range was $m / z 10-500$ (1.5 s/scan).

\section{Results and Discussion}

The ionization mechanism in negative ion APPI was studied by analyzing a series of compounds in 17 different solvent systems (Figure 1, Table 1). The studied compounds possess either high gas-phase acidities, positive electron affinities (EA), or both (Table 2) and can therefore be ionized in negative ion mode either by proton transfer to form a deprotonated molecule, or by electron capture or charge exchange to form a negative molecular ion (Table 3). On the other hand, the wide variety of solvent systems of different polarities and gas-phase acidities provides a possibility to study systematically the ionization process as well as the solvent effect in negative ion APPI. Furthermore, the solvent compositions studied are commonly used in liquid chromatography and therefore also interesting in the view of applications.

\section{Solvent and Background Ions}

The background spectra of the neutral (Solvents 1-7, except chloroform) and basic solvents (Solvents 10 and 15) were very similar and showed the following common ions: $m / z$ 46, 59, 60, 61, 77, and 117 (Table 4). In the
Table 3. The reactions in negative ion APPI

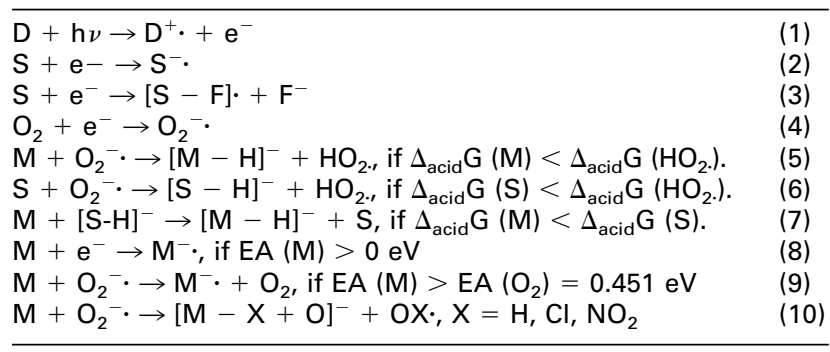

earlier work these ions were also observed when only toluene was introduced to the APPI source [7]. This suggests that the ions originate from ionization of toluene or atmospheric gases present in the ion source, e.g., $\left[\mathrm{NO}_{2}\right]^{-}(\mathrm{m} / \mathrm{z} 46),\left[\mathrm{CO}_{3}\right]^{-}(\mathrm{m} / \mathrm{z} 60)$, and $\left[\mathrm{HCO}_{3}\right]^{-}(\mathrm{m} / \mathrm{z}$ 61). Chloroform (Solvent 2) was an exception as it showed $\mathrm{Cl}^{-}$and other ions with characteristic chlorine isotope patterns, probably formed by dissociative electron capture (Reaction 3, Table 3) and gas-phase reactions between fragments of chloroform and other gasphase components (Table 4 ). The background changed radically when acids or ammonium acetate (Solvents 8 , $9,11,12,13,14,16,17)$ were introduced to the system, and very abundant deprotonated molecules of the acids $\left(\left[\mathrm{CH}_{3} \mathrm{COO}\right]^{-}\right.$, $[\mathrm{HCOO}]^{-}$, and $\left.\left[\mathrm{CF}_{3} \mathrm{COO}\right]^{-}\right)$were observed instead of the ions $m / z 46,59,60,61$, and 77 . This is probably due to neutralization of the atmospheric anions $\left(\left[\mathrm{NO}_{2}\right]^{-},\left[\mathrm{CO}_{3}\right]^{-},\left[\mathrm{HCO}_{3}\right]^{-}\right.$etc. $)$via proton transfer by the components of high gas-phase acidity. In addition, all the background spectra contained several ions that could not be identified. Furthermore, the mass spectrometer used discriminates against low $\mathrm{m} / \mathrm{z}$ values, leaving many important ions, such as $\mathrm{O}_{2}^{-\cdot}$ and $\mathrm{CH}_{3} \mathrm{O}^{-}$ undetectable.

\section{Ionization of the Analytes}

Proton transfer. 2-Naphthoic acid (A), 2-naphthol (B), 3-methyl-2,5-furandione (C), and 2,5-furandione (D) were mostly ionized by proton transfer, forming [M $\mathrm{H}]^{-}$ions (Figure 2). In addition, fragments, solvent adducts or gas-phase reaction products and substitution products were observed in the spectra of these compounds (Table 5). Deprotonation of the analyte is possible for compounds that have higher gas-phase acidity than the reactant molecules in the ion source, i.e., their $\Delta \mathrm{G}_{\text {acid }}$ is below that of the reactant molecules. Alternatively, it can be presented that deprotonation of the analyte takes place if the proton affinity (PA) of the deprotonated analyte is lower than that of the reactant anion. Energetics for the studied compounds and solvents are presented in Table 2 . However, for the studied analytes, only the gas-phase acidity of 2-naphthol is presented in the literature, being $1408 \mathrm{~kJ} \mathrm{~mol}^{-1}$ [10]. The gas-phase acidity of 2-naphthoic acid can be estimated to be about $1370 \mathrm{~kJ} \mathrm{~mol}^{-1}$ based on the difference of about $40 \mathrm{~kJ} \mathrm{~mol}^{-1}$ between the gas-phase acidities of 
Table 4. The background ions of the solvents formed in APPI

\begin{tabular}{|c|c|}
\hline Solvent & lons observed \\
\hline Hexane & $\begin{array}{l}42(21)\left[\mathrm{CHO}^{-}, 45(15), 46(30)\left[\mathrm{NO}_{2}\right]^{-}, 59(27), 60(100)\left[\left(\mathrm{N}_{2}\right) \mathrm{O}_{2}\right]^{-} ;\left[\mathrm{CO}_{3}\right]^{-}, 61(83)\left[\mathrm{HCO}_{3}\right]^{-} \text {, }\right. \\
\quad 77(25), 100(18), 117(77), 121(16)\end{array}$ \\
\hline Chloroform & 35 (15) [CI] $]^{-}, 93$ (87), 95 (58), 97 (13), 109 (13), 115 (17), 117 (100), 118 (14), 135 (41), 137 (17) \\
\hline Water & $\begin{array}{l}42(14)\left[\mathrm{CNO}^{-}, 46(56)\left[\mathrm{NO}_{2}\right]^{-}, 59(27), 60(65)\left[\left(\mathrm{N}_{2}\right) \mathrm{O}_{2}\right]^{-} ;\left[\mathrm{CO}_{3}\right]^{-}, 61(100)\left[\mathrm{HCO}_{3}\right]^{-}, 77(25),\right. \\
\quad 93(17), 107(28), 117(70), 121(19)\end{array}$ \\
\hline Methanol & $\begin{array}{l}46(67)\left[\mathrm{NO}_{2}\right]^{-}, 59(28) 60(57)\left[\left(\mathrm{N}_{2}\right) \mathrm{O}_{2}\right]^{-} ;\left[\mathrm{CO}_{3}\right]^{-}, 61(26)\left[\mathrm{HCO}_{3}\right]^{-}, 75(68), 77(47), 100(29) \\
\quad 117(95), 123(28), 137(100)\end{array}$ \\
\hline Acetonitrile & $42(92)[\mathrm{CNO}]^{-}, 45(18), 46(22)\left[\mathrm{NO}_{2}\right]^{-}, 59(16), 100(17), 107(13), 117(100), 118(17), 121(12)$ \\
\hline Water/methanol & $\begin{array}{l}45(27), 46(72)\left[\mathrm{NO}_{2}\right]^{-}, 59(44), 60(64)\left[\left(\mathrm{N}_{2}\right) \mathrm{O}_{2}\right]^{-} ;\left[\mathrm{CO}_{3}\right]^{-}, 61(86)\left[\mathrm{HCO}_{3}\right]^{-}, 75(39), 77(49), \\
\quad 100(24), 117(100), 121(21)\end{array}$ \\
\hline Water/acetonitrile & $\begin{array}{l}42(85)\left[\mathrm{CNO}^{-}, 45(26), 46(37)\left[\mathrm{NO}_{2}\right]^{-}, 59(31), 60(34)\left[\left(\mathrm{N}_{2}\right) \mathrm{O}_{2}\right]^{-} ;\left[\mathrm{CO}_{3}\right]-, 61(16)\left[\mathrm{HCO}_{3}\right]^{-},\right. \\
\quad 100(16), 107(24), 117(100), 121(22)\end{array}$ \\
\hline Water/methanol/HAc & $59(100)\left[\mathrm{CH}_{3} \mathrm{COO}\right]^{-}, 117(34), 157(22), 142(11)$ \\
\hline Water/methanol/ $\mathrm{NH}_{4} \mathrm{Ac}$ & $59(100)\left[\mathrm{CH}_{3} \mathrm{COO}\right]^{-}, 117(50), 141(93), 142(9.0), 157(20)$ \\
\hline Water/methanol/ $\mathrm{NH}_{4} \mathrm{OH}$ & $\begin{array}{l}45(38), 46(45)\left[\mathrm{NO}_{2}\right]^{-}, 59(61), 60(52)\left[\left(\mathrm{N}_{2}\right) \mathrm{O}_{2}\right]^{-} ;\left[\mathrm{CO}_{3}\right]^{-}, 61(86)\left[\mathrm{HCO}_{3}\right]^{-}, 73(22), 75(39), \\
\quad 77(39), 95(31), 117(100)\end{array}$ \\
\hline Water/methanol/CHOOH & $45(100)[\mathrm{HCOO}]^{-}, 113(93), 117(43), 129(17)$ \\
\hline Water/methanol/TFA & $\begin{array}{l}69(23)\left[\mathrm{CF}_{3}\right]^{-}, 113(100)\left[\mathrm{CF}_{3} \mathrm{COO}^{-}, 227(100)\left[2 \times \mathrm{CF}_{3} \mathrm{COOH}-\mathrm{H}\right]^{-}, 249(52)\right. \\
{\left[\mathrm{CF}_{3} \mathrm{COONa}^{-} \mathrm{CF}_{3} \mathrm{COO}\right]^{-}, 265(29)\left[\mathrm{CF}_{3} \mathrm{COOK}+\mathrm{CF}_{3} \mathrm{COO}^{-}, 385(12)\right.}\end{array}$ \\
\hline Water/acetonitrile/HAc & $59(100)\left[\mathrm{CH}_{3} \mathrm{COO}^{-}, 117(35), 119(6.4), 139(8.1), 141(99), 157(22), 212\right.$ (9.2) \\
\hline Water/acetonitrile/ $\mathrm{NH}_{4} \mathrm{Ac}$ & $59(100)\left[\mathrm{CH}_{3} \mathrm{COO}\right]^{-}, 117(53), 118(8.1), 119(7.5), 141(92), 157(19)$ \\
\hline Water/acetonitrile/ $\mathrm{NH}_{4} \mathrm{OH}$ & $\begin{array}{l}42(68)\left[\mathrm{CNO}^{-}, 45(23), 46(19)\left[\mathrm{NO}_{2}\right]^{-}, 59(32), 60(24)\left[\left(\mathrm{N}_{2}\right) \mathrm{O}_{2}\right]^{-} ;\left[\mathrm{CO}_{3}\right]^{-}, 61(26)\left[\mathrm{HCO}_{3}\right]^{-} \text {, }\right. \\
\quad 95(35), 107(18), 117(100), 121(18)\end{array}$ \\
\hline Water/acetonitrile/CHOOH & $45(91)[\mathrm{HCOO}]^{-}, 113(100), 117(41), 129(19), 181(9.3)$ \\
\hline Water/acetonitrile/TFA & $\begin{array}{l}69(65), 113(64)\left[\mathrm{CF}_{3} \mathrm{COO}\right]^{-}, 114(32), 205(48), 226(17), 227(76)\left[2 \mathrm{xCF}_{3} \mathrm{COOH}-\mathrm{H}\right]^{-}, 249(100) \\
\quad\left[\mathrm{CF}_{3} \mathrm{COONa}+\mathrm{CF}_{3} \mathrm{COO}\right]^{-}, 265(43)\left[\mathrm{CF}_{3} \mathrm{COOK}+\mathrm{CF}_{3} \mathrm{COO}\right]^{-}, 267(17), 385(57)\end{array}$ \\
\hline
\end{tabular}

Only 10 most intensive ions were included in the Table. lons that had intensity $<6 \%$ of the maximum were not included.

$\mathrm{HAc}=$ acetic acid

$\mathrm{NH}_{4} \mathrm{Ac}=$ ammonium acetate

$\mathrm{NH}_{4} \mathrm{OH}=$ ammonium hydroxide

$\mathrm{CHOOH}=$ formic acid

TFA $=$ trifluoroacetic acid

phenol (1432 kJ mol $\left.{ }^{-1}\right)$ and benzoic acid $\left(1393 \mathrm{~kJ} \mathrm{~mol}^{-1}\right)$ [10]. Unfortunately the gas-phase acidities for 3-methyl2,5-furandione and 2,5-furandione could not be found from the literature, but they are assumed to be very low.

The ionization of Compounds A-D (Figure 1) via deprotonation was efficient in the neutral and basic solvents except in chloroform (Solvents 1, 3, 4, 5, 6, 7, 10, and 15, Table 1, Figure 2). This indicates that these solvents produce reactant ions with low gas-phase acidities, such as hydroxide ions, deprotonated molecules of methanol and acetonitrile or their clusters. Interestingly, use of hexane as the solvent did not suppress the formation of $[\mathrm{M}-\mathrm{H}]^{-}$, although hexane cannot produce stable gas-phase reactant ions capable of proton transfer. This suggests that species other than those originating from the solvent are present in the ion source and can take part in the proton transfer with the analytes of high gas-phase acidity. Horning et al. have shown in an earlier work that $\mathrm{O}_{2}^{-}$, formed from oxygen by electron capture (Table 3, Reaction 4), plays an important role in APCI and the same may be true in APPI [11]. $\mathrm{O}_{2}^{-\cdot}$ is a relatively strong gas-phase base $\left(\Delta \mathrm{G}_{\text {acid }}\right.$ of $\mathrm{HO}_{2}=1451 \mathrm{~kJ} \mathrm{~mol}^{-1}$, Table 2$)$ and can therefore react with the acidic analytes or solvents by proton transfer (Table 3, Reactions 5 and 6). Another species that may influence the proton transfer reactions is $\mathrm{NO}_{2}{ }^{-}$, probably formed by electron capture (Table 3,
Reaction 2, EA $\left.\left(\mathrm{NO}_{2}\right)=2.273 \mathrm{eV}\right)$ and observed in the background of most of the solvents (Table 4). $\mathrm{HNO}_{2}$ is a relatively strong gas-phase acid $\left(\Delta \mathrm{G}_{\text {acid }}=1396 \mathrm{~kJ}\right.$ $\mathrm{mol}^{-1}$ ) [10] and therefore $\mathrm{NO}_{2}^{-}$can deprotonate only stronger acids, in our case 2-naphthoic acid (Table 2). However, $\mathrm{NO}_{2}^{-}$may react with other species in the gas-phase and produce new unidentified background ions, which may be involved in protonation and deprotonation of the analytes (Table 4).

The use of halogenated solvents, chloroform and TFA (Solvents 2, 12, and 17), inhibited the ionization of all the compounds (Figure 2). The ionization process in APPI is assumed to be initiated by thermal electrons formed in the photoionization of toluene (Table 3, Reaction 1), as supported by earlier work, where measurements made without toluene decreased dramatically the sensitivity in negative ion APPI [7]. The halogenated solvents capture efficiently thermal electrons, due to their positive electron affinities (Table 2) [10]. The formation of $\mathrm{O}_{2}^{-\cdot}$ (Table 3, Reaction 4) and thus also the deprotonation of the acidic analytes via Reactions 5-7 (Table 3) are inhibited due to the decreased number of electrons. Another reason for poor ionization efficiency with TFA is its high gas-phase acidity (see discussion below and Table 2). The background spectrum of chloroform does not show molecular anion of chloroform, as it probably undergoes dissociative elec- 

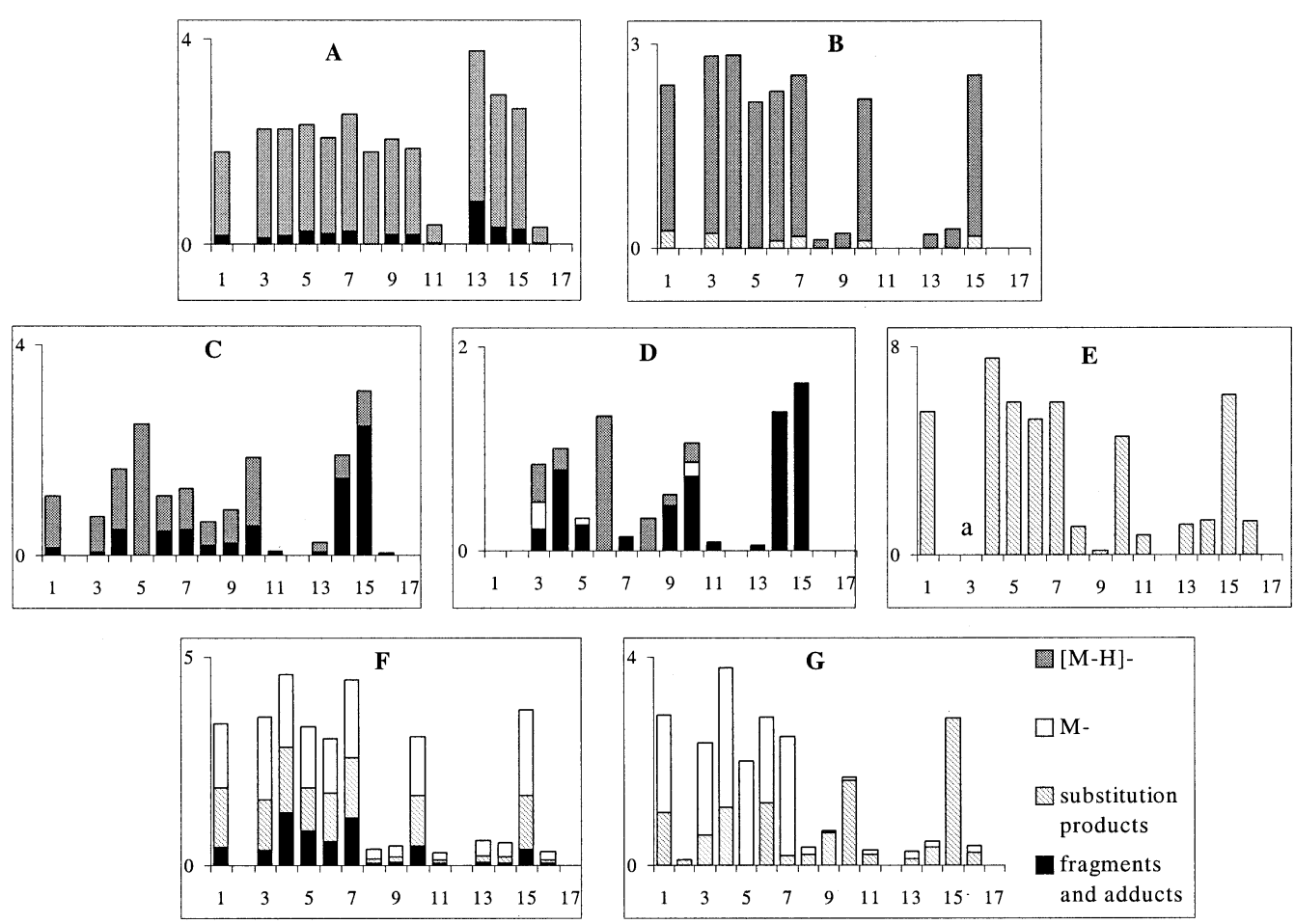

Figure 2. The absolute abundances of the total ion currents and the relative proportions of $[\mathrm{M}-\mathrm{H}]^{-}$, $\mathrm{M}^{-\cdot}$, fragments and adducts and substitution products. $\mathrm{X}=$ Solvents 1-17 (Table 1), $\mathrm{Y}=$ absolute abundance in arbitrary units. The letters indicate the studied compounds: $\mathrm{A}=2$-naphthoic acid, $\mathrm{B}=$ 2-naphthol, $\mathrm{C}=3$-methyl-2,5-furandione, $\mathrm{D}=2$,5-furandione, $\mathrm{E}=$ hexachlorobenzene, $\mathrm{F}=1,4$ dinitrobenzene, and $\mathrm{G}=1,4$-naphthoquinone; $\mathrm{a}=$ the compound could not be dissolved in the solvent in question and was therefore left out of the study.

tron capture like reported in low pressure chemical ionization [12]. Therefore, the formation of $\mathrm{HCl}$ is also possible although it cannot be confirmed with the data available. If $\mathrm{HCl}$ is present in the gas-phase, it, as a strong gas-phase acid inhibits deprotonation reactions.

The solvents that contained formic acid or trifluoroacetic acid (Solvents 11,12, 16, and 17, Table 1) seriously deteriorated the ionization of Analytes A-D and those containing ammonium acetate or acetic acid (Solvents 8 , 9,13 , and 14, Table 1) deteriorated the ionization of Analytes B-D (Figure 2). The signal decreased as the gas-phase acidity of the additive was increased, being poor with formic acid and nonexistent with trifluoroacetic acid. The effect of TFA is probably partly explained by its high EA, but the results can also be explained simply by comparing the gas-phase acidities of the additives and the analytes (Table 2) [10]. The gas-phase acidity of TFA is significantly higher than those of the analytes (Compounds A-D) and therefore deprotonation of the analytes is not possible. Also, the gas-phase acidity of formic acid is high enough to prevent deprotonation of Compounds B-D and to decrease significantly the ionization efficiency of 2-naphthoic acid. However, in acetic acid and ammonium acetate, the signal of 2-naphthoic acid was intense, unlike that of Compounds B-D, since the gas-phase acidity of 2-naphthoic acid $\left(\Delta \mathrm{G}_{\text {acid }}=1370 \mathrm{~kJ} \mathrm{~mol}^{-1}\right)$ is higher than that of acetic acid $\left(\Delta \mathrm{G}_{\text {acid }}=1429 \mathrm{~kJ} \mathrm{~mol}^{-1}\right)$.
The gas-phase acidities of 2-naphthol and the rest of the compounds are too low for efficient ionization in presence of acetic acid or ammonium acetate.

The gas-phase acidities of 3-methyl-2,5-furandione and 2,5-furandione (Compounds $\mathrm{C}$ and $\mathrm{D}$ ) are assumed to be very low and thus the deprotonation is not expected to be possible even with neutral eluents. However, intense $[\mathrm{M}-1]^{-}$ions were observed in the spectra of both compounds in many of the solvents (Figure 2). In addition, the spectra of both anhydrides showed unexpectedly stable $[\mathrm{M}+17]^{-}$ions (Table 5). As the anhydrides are easily hydrolyzed to dicarboxylic acids by water, it is possible that the ion $[\mathrm{M}+17]^{-}$is in fact the deprotonated 2-methyl-2-butenedioic/2butenedioic acid, which has a sufficiently high gasphase acidity for efficient ionization by proton transfer. The product ion spectra of $[\mathrm{M}+17]^{-}$of the anhydrides and $[\mathrm{M}-\mathrm{H}]^{-}$of the dicarboxylic acids were identical, which indicates that the $[\mathrm{M}+17]^{-}$observed in the anhydride spectra is indeed the dicarboxylic acid formed in hydrolysis of the anhydride. Thus, the [M $1]^{-}$ion observed in the anhydride APPI-MS spectra may have been formed by loss of water from $[\mathrm{M}+17]^{-}$. The fact that the ion $[\mathrm{M}+17]^{-}$was also observed in hexane indicates that the atmospheric moisture is enough for the hydrolysis reaction to take place. In addition to the hydrolysis products, ions $[\mathrm{M}+31]^{-}$and $[\mathrm{M}+40]^{-}$, which probably are products of solvolysis, 
Table 5. Ions of the studied compounds observed in hexane, methanol and acetonitrile by using APPI

\begin{tabular}{|c|c|c|c|}
\hline & $(\mathrm{M}-\mathrm{H})^{-}$ & $\mathrm{M}^{-\bullet}$ & Fragments and adducts \\
\hline \multicolumn{4}{|c|}{ 2-Naphthoic acid (MW = 172) } \\
\hline 1. Hexane & $171(100)$ & - & $127(9.7)\left[\mathrm{M}-\mathrm{H}-\mathrm{CO}_{2}\right]^{-}$ \\
\hline 4. Methanol & $171(100)$ & - & $127(7.6)\left[\mathrm{M}-\mathrm{H}-\mathrm{CO}_{2}\right]^{-}, 226(7.8), 239(13)$ \\
\hline 5. Acetonitrile & $171(100)$ & - & $127(12)\left[\mathrm{M}-\mathrm{H}-\mathrm{CO}_{2}\right]^{-}$ \\
\hline \multicolumn{4}{|c|}{ 2-Naphthol (MW = 144) } \\
\hline 1. Hexane & $143(100)$ & - & $158(18)\left[\mathrm{M}-2 \mathrm{H}+\mathrm{O}^{-}, 159(18)\left[\mathrm{M}-\mathrm{H}+\mathrm{O}^{-}, 173(11)\right.\right.$ \\
\hline 4. Methanol & $143(100)$ & - & - \\
\hline 5. Acetonitrile & $143(100)$ & - & $158(7.8)[\mathrm{M}-2 \mathrm{H}+\mathrm{O}]^{-} 159(8.3)\left[\mathrm{M}-\mathrm{H}+\mathrm{O}^{-}, 182(24)\right.$ \\
\hline \multicolumn{4}{|c|}{ 3-Methyl-2,5-furandione ( $\mathrm{MW}=112$ ) } \\
\hline 1. Hexane & $111(100)$ & - & $129(33)[M+17]^{-}$ \\
\hline 4. Methanol & $111(100)$ & - & $85(6.6), 143(43)\left[\mathrm{M}+\mathrm{CH}_{3} \mathrm{O}\right]^{-}$ \\
\hline 5. Acetonitrile & $111(100)$ & - & $\begin{array}{c}85(5.1), 126(7.1), 149(6.2), 150(85), 152(11) \\
{\left[\mathrm{M}+\mathrm{CH}_{2} \mathrm{CN}\right]^{-}, 189(13), 223(8.3)[2 \mathrm{M}-\mathrm{H}]^{-}}\end{array}$ \\
\hline \multicolumn{4}{|c|}{ 2,5-Furandione $(\mathrm{MW}=98)$} \\
\hline 1. Hexane & - & - & $115(95)[\mathrm{M}+17]^{-}$ \\
\hline 4. Methanol & $97(15)$ & $98(22)$ & $129(100)\left[\mathrm{M}+\mathrm{CH}_{3} \mathrm{O}\right]^{-}$ \\
\hline 5. Acetonitrile & - & $98(56)$ & $\begin{array}{c}71(9.2), 82(9.5), 94(25), 96(37), 115(29)[\mathrm{M}+17]^{-}, \\
124(6.2), 129(8.1), 138(100)\left[\mathrm{M}+\mathrm{CH}_{2} \mathrm{CN}\right]^{-}\end{array}$ \\
\hline \multicolumn{4}{|c|}{ Hexachlorobenzene $(\mathrm{MW}=282)$} \\
\hline 1. Hexane & - & - & $\begin{array}{l}263(73)\left[\mathrm{M}-\mathrm{Cl}+\mathrm{O}^{-}, 265(100), 267(80), 269 \text { (37), }\right. \\
\quad 271(6.5)\end{array}$ \\
\hline 4. Methanol & - & - & $\begin{array}{l}263(75)\left[\mathrm{M}-\mathrm{Cl}+\mathrm{O}^{-}, 265(100), 267 \text { (83), } 269 \text { (38), }\right. \\
\quad 271 \text { (7.7), } 323(5.2)\end{array}$ \\
\hline 5. Acetonitrile & - & - & $\begin{array}{l}263(72)\left[\mathrm{M}-\mathrm{Cl}+\mathrm{O}^{-}, 265(100), 267(79), 269(33),\right. \\
271(5.9)\end{array}$ \\
\hline \multicolumn{4}{|c|}{ 1,4-Dinitrobenzene (MW = 168) } \\
\hline 1. Hexane & - & $168(90)$ & $\begin{array}{l}123(6.7)\left[\mathrm{M}-\mathrm{NO}_{2}+\mathrm{H}\right]^{-}, 138(100)\left[\mathrm{M}-\mathrm{NO}_{2}+\mathrm{O}^{-}\right. \\
152(6.7)\left[\mathrm{M}-\mathrm{O}^{-}, 154(9.5)\right.\end{array}$ \\
\hline 4. Methanol & - & $168(100)$ & $\begin{array}{l}121(14)\left[\mathrm{M}-\mathrm{NO}_{2}-\mathrm{H}\right]^{-}, 137(30)\left[\mathrm{M}-\mathrm{NO}_{2}+\mathrm{O}-\mathrm{H}\right]^{-} \\
138(56)\left[\mathrm{M}-\mathrm{NO}_{2}+\right]^{-}, 154(7.1)\end{array}$ \\
\hline 5. Acetonitrile & & $168(100)$ & 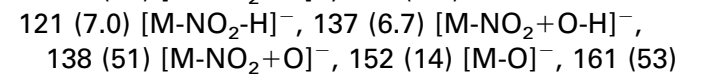 \\
\hline \multicolumn{4}{|c|}{ 1,4-Naphthoquinone ( $\mathrm{MW}=158)$} \\
\hline 1. Hexane & - & $158(100)$ & $\begin{array}{l}145(63)[\mathrm{M}-\mathrm{H}+\mathrm{O}-\mathrm{CO}]^{-}, 173(56)\left[\mathrm{M}-\mathrm{H}+\mathrm{O}^{-}, 198(14)\right. \\
{[\mathrm{M}-\mathrm{H}+2 \mathrm{O}]^{-}, 191(68)}\end{array}$ \\
\hline 4. Methanol & - & $158(100)$ & $145(27)[\mathrm{M}-\mathrm{H}+\mathrm{O}-\mathrm{CO}]^{-}, 173(14)\left[\mathrm{M}-\mathrm{H}+\mathrm{O}^{-}, 191(17)\right.$ \\
\hline 5. Acetonitrile & - & $158(100)$ & $\begin{array}{l}145(6.5)[\mathrm{M}-\mathrm{H}+\mathrm{O}-\mathrm{CO}]^{-}, 191(6.3)[\mathrm{M}+33]^{-}, 196 \text { (27) } \\
\quad 198(21),\left[\mathrm{M}+\mathrm{CH}_{3} \mathrm{CH}-\mathrm{H}\right]^{-}\end{array}$ \\
\hline
\end{tabular}

were observed in the anhydride spectra when methanol and acetonitrile, respectively, were present (Table 5).

Electron capture/charge exchange The formation of negative molecular ion $\mathrm{M}^{-\cdot}$ by electron capture or charge exchange (Table 3, Reactions 8 and 9, respectively) is possible for compounds of positive EA-in this study 1,4-dinitrobenzene, 1,4-naphthoquinone, 3-methyl-2,5furandione, 2,5-furandione, and hexachlorobenzene (Table 2). Of these compounds, only 1,4-dinitrobenzene and 1,4-naphthoquinone showed intense $\mathrm{M}^{-}$, in addition a weak $\mathrm{M}^{-\cdot}$ was observed in 2,5-furandione spectra in Solvents 3, 4, 5, and 10 (Figure 2, Table 5). Hexachlorobenzene spectra showed only a phenoxide ion [M $\mathrm{Cl}+\mathrm{O}^{-}$formed by a substitution reaction. Similar phenoxide ions were also observed in 1,4-naphthoquinone and 1,4-dinitrobenzene spectra.

Just as in case of deprotonation, the most abundant $\mathrm{M}^{-\cdot}$ ions of the compounds of positive EA were formed with the neutral and basic solvents (chloroform being an exception), but the ionization efficiency was poor when additives that produce high abundances of low PA reactant anions (Table 4, Solvents 8, 9, 11, 12, 13, 14, 16 , and 17) were introduced to the system. This is probably due to the neutralization of reactant ions capable of charge exchange reaction. The main reason may be the neutralization of $\mathrm{O}_{2}^{-\cdot}$ by proton transfer, which is possible with TFA, formic acid, acetic acid, and ammonium acetate, since $\mathrm{PA} \mathrm{O}_{2}^{-}$is higher than those of $\left[\mathrm{CF}_{3} \mathrm{COO}\right]^{-}$, $[\mathrm{HCOO}]^{-}$, and $\left[\mathrm{CH}_{3} \mathrm{COO}\right]^{-}$(Table 2 ). Similarly, with deprotonation the formation of $\mathrm{M}^{-\cdot}$ was totally prevented in halogenated solvents that possess high EA (Solvents 2, 12, and 17, Figure 2). Again, the halogenated solvents capture thermal electrons, and an insufficient amount is left for the ionization of the analytes by electron capture. The formation of $\mathrm{O}_{2}^{-\cdot}$ is also inhibited, since chloroform possesses higher EA than $\mathrm{O}_{2}$ (Table 2) and therefore charge exchange between $\mathrm{O}_{2}^{-\cdot}$ and the analyte does not take place. However, many of the analytes possess higher EA than 
Table 6. Ions of the studied compounds observed in hexane, methanol and acetonitrile by using APCI

\begin{tabular}{|c|c|c|c|}
\hline & $(\mathrm{M}-\mathrm{H})^{-}$ & $\mathrm{M}^{-\bullet}$ & Fragments and adducts \\
\hline \multicolumn{4}{|c|}{ 2-Naphthoic acid (MW = 172) } \\
\hline 1. Hexane & $171(27)$ & - & - \\
\hline 4. Methanol & $171(89)$ & - & $226(30)$ \\
\hline 5. Acetonitrile & $171(100)$ & - & - \\
\hline \multicolumn{4}{|c|}{ 2-Naphthol (MW =144) } \\
\hline 1. Hexane & $143(100)$ & - & $158(31)[\mathrm{M}-2 \mathrm{H}+\mathrm{O}]^{-}$ \\
\hline 4. Methanol & $143(100)$ & - & - \\
\hline 5. Acetonitrile & $143(100)$ & - & $158(9.3)[\mathrm{M}-2 \mathrm{H}+\mathrm{O}]^{-}$ \\
\hline \multicolumn{4}{|c|}{ 3-Methyl-2,5-furandione (MW = 112) } \\
\hline 1. Hexane & $111(100)$ & - & - \\
\hline 4. Methanol & $111(100)$ & - & 143 (33) $\left[\mathrm{M}+\mathrm{CH}_{3} \mathrm{O}\right]^{-}, 198(18)$ \\
\hline 5. Acetonitrile & $111(100)$ & - & - \\
\hline \multicolumn{4}{|c|}{ 2,5-Furandione ( $\mathrm{MW}=98)$} \\
\hline 1. Hexane & - & - & - \\
\hline 4. Methanol & $97(8.2)$ & $98(82)$ & $129(100)\left[\mathrm{M}+\mathrm{CH}_{3} \mathrm{O}\right]^{-}, 184(25), 336$ (8.8) \\
\hline 5. Acetonitrile & - & $98(100)$ & - \\
\hline \multicolumn{4}{|c|}{ Hexachlorobenzene (MW = 282) } \\
\hline 1. Hexane & - & - & $263(65)[\mathrm{M}-\mathrm{Cl}+\mathrm{O}]^{-}, 265(100), 267(70), 269$ (27) \\
\hline 4. Methanol & - & - & $\begin{array}{l}111(12), 122(11), 123(18), 125(12), 127(14), 137 \\
(21), 139(57), 155(23), 157(9.4), 171(9.2), 263 \\
(67)\left[\mathrm{M}-\mathrm{Cl}+\mathrm{O}^{-}, 265(100), 267(75), 269(28)\right.\end{array}$ \\
\hline 5. Acetonitrile & - & - & $263(61)[\mathrm{M}-\mathrm{Cl}+\mathrm{O}]^{-}, 265(100), 267(70), 269(24)$ \\
\hline \multicolumn{4}{|c|}{ 1,4-Dinitrobenzene (MW = 168) } \\
\hline 1. Hexane & - & $168(100)$ & $138(47)\left[\mathrm{M}-\mathrm{NO}_{2}+\mathrm{O}\right]^{-}$ \\
\hline 4. Methanol & - & $168(100)$ & $\begin{array}{l}121(57)\left[\mathrm{M}-\mathrm{NO}_{2}-\mathrm{H}\right]^{-}, 137(19)\left[\mathrm{M}-\mathrm{NO}_{2}+\mathrm{O}-\mathrm{H}\right]^{-}, \\
138(36)\left[\mathrm{M}-\mathrm{NO}_{2}+\mathrm{O}^{-}, 165(25), 219(34), 223(18),\right. \\
239(48), 313(18), 461(21)\end{array}$ \\
\hline 5. Acetonitrile & - & $168(100)$ & $138(31)\left[\mathrm{M}-\mathrm{NO}_{2}+\mathrm{O}\right]^{-}$ \\
\hline \multicolumn{4}{|c|}{ 1,4-Naphthoquinone (MW = 158) } \\
\hline 1. Hexane & - & $158(100)$ & - \\
\hline 4. Methanol & - & $158(100)$ & - \\
\hline 5. Acetonitrile & - & $158(100)$ & - \\
\hline
\end{tabular}

chloroform and therefore the charge exchange reaction between $\mathrm{M}^{-*}$ of chloroform and the analytes would be expected to take place (Table 2) [10]. Yet, no such reaction is observed. This is probably because instead of the $\mathrm{M}^{-\cdot}$ ion of chloroform other high EA chlorinated species, such as $\mathrm{Cl}^{-}$, which cannot react with the analyte via charge exchange, are formed (Tables 2 and 4). It is also possible that the gas-phase reactions with chloroform produce $\mathrm{HCl}, \mathrm{HOCl}$, or other acids that neutralize $\mathrm{O}_{2}^{-}$and thus inhibit the charge exchange reaction between the analyte and $\mathrm{O}_{2}^{-}$.

$\mathrm{NO}_{2}^{-}$, observed in the background spectra (Table 4), may also affect the ionization processes in negative ion APPI. $\mathrm{NO}_{2}^{-}$is possibly formed in the gas-phase by electron capture from $\mathrm{NO}_{2}$, which is a common impurity in the atmosphere. To study the effect of $\mathrm{NO}_{2}$ on the ionization process of compounds $\mathrm{E}$ and $\mathrm{G}, 510 \mathrm{~mol}-\mathrm{ppm}$ $\mathrm{NO}_{2}$ in nitrogen (Oy Aga Ab, Riihimäki, Finland) was introduced to the APPI source as the auxiliary gas instead of high purity $\mathrm{N}_{2}$. No signal of the analytes $\mathrm{E}$ and $\mathrm{G}$ (Figure 1) could be observed in the spectra with $\mathrm{NO}_{2} . \mathrm{NO}_{2}$ has higher EA (2.273 eV, Table 2) [10] than any of the studied solvents or analytes and may therefore consume thermal electrons. It may also neutralize
$\mathrm{O}_{2}^{-\cdot}$ and $\mathrm{M}^{-\cdot}$ ions of analytes by charge exchange, which decreases the sensitivity. However, the concentration of $\mathrm{NO}_{2}$ in the gas-phase is probably low, as the amount of thermal electrons in the usual conditions seems to be high enough for the efficient ionization of the analytes.

Substitution reaction In addition to $\mathrm{M}^{-*}$ ions, substitution products of form $\left[\mathrm{M}-\mathrm{Cl}+\mathrm{O}^{-}\right.$and $[\mathrm{M}-\mathrm{H}+$ $\mathrm{O}^{-}$were observed in hexachlorobenzene and 1,4-naphthoquinone spectra, respectively (Figure 2, Table 5). In 1,4-dinitrobenzene spectra ion $[\mathrm{M}-30]^{-}$was observed, which can be either a substitution product $\left[\mathrm{M}-\mathrm{NO}_{2}+\right.$ $\mathrm{O}^{-}$or a fragment $\left[\mathrm{M}-\mathrm{NO}^{-}\right.$formed by rearrangement. Substitution products like this have been reported to be formed in a substitution reaction between $\mathrm{O}_{2}^{-\cdot}$ and polychlorinated, nitro- or other aromatic compounds (Table 3, Reaction 10) in APPI [7] and APCI [11, 13]. The reaction can be utilized to enhance the ionization efficiency when this kind of compounds are analyzed in negative ion mode [11].

In hexachlorobenzene spectra only phenoxide ions were observed, whereas for 1,4-dinitrobenzene and 1,4-naphthoquinone the formation of phenoxide ions was clearly competitive with the formation of $\mathrm{M}^{-*}$. The 

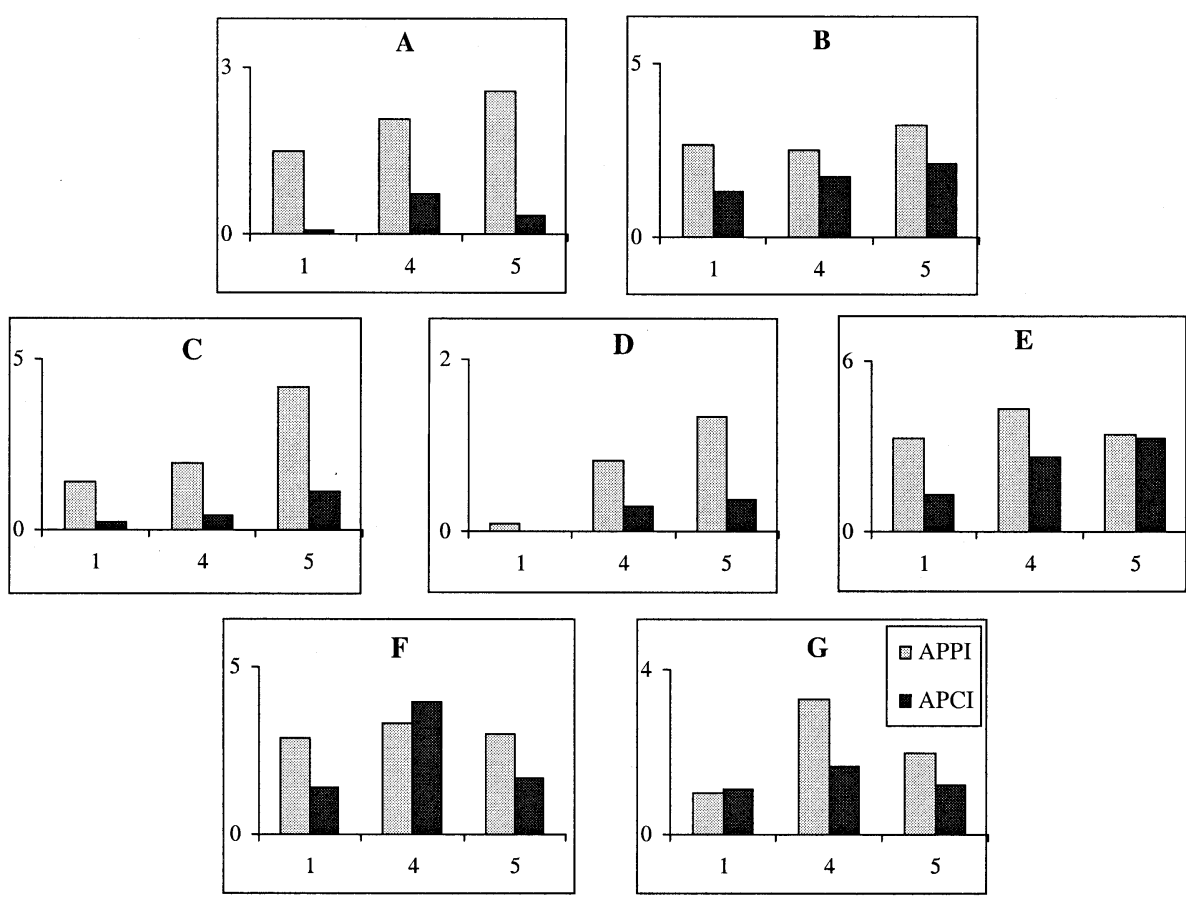

Figure 3. The absolute abundances of the total ion currents in APPI and APCI. $X=$ Solvents 1,4 , and 5 (Table 1), $\mathrm{Y}=$ absolute abundance in arbitrary units. The letters indicate the studied compounds: A = 2-naphthoic acid, $\mathrm{B}=2$-naphthol, $\mathrm{C}=3$-methyl-2,5-furandione, $\mathrm{D}=2,5$ - furandione, $\mathrm{E}=$ hexachlorobenzene, $\mathrm{F}=1,4$-dinitrobenzene, and $\mathrm{G}=1,4$-naphthoquinone.

relative abundance ratio of $\mathrm{M}^{-*} /\left[\mathrm{M}-\mathrm{X}+\mathrm{O}^{-}\right.$was constant in all the solvents for 1,4-dinitrobenzene and hexachlorobenzene, but in 1,4-naphthoquinone spectra the proportion of $\left[\mathrm{M}-\mathrm{X}+\mathrm{O}^{-}\right.$increased in solvents that contained additives, whereas in other solvents the formation of $\mathrm{M}^{-\cdot}$ was more efficient (Figure 2, Table 5).

Although $\mathrm{O}_{2}^{-\cdot}$ is not observed in the background spectra, the results indicate that oxygen is present in the APPI ion source. Only high purity nitrogen was used in the APPI operation but as the ion source is operated in atmospheric pressure, the most probable source for $\mathrm{O}_{2}$ is the ambient air. In fact, when high purity nitrogen was replaced by purified air in the APPI operation, the proportion of phenoxide ions for 1,4-naphthoquinone increased (with $\mathrm{N}_{2} \mathrm{M}^{-*} /\left[\mathrm{M}-\mathrm{H}+\mathrm{O}^{-}=1.2\right.$, with air $\mathrm{M}^{-*} /\left[\mathrm{M}-\mathrm{H}+\mathrm{O}^{-}=0.5\right)$, which indicates that the concentration of oxygen has an effect on the substitution reaction. However, the proportion of substitution products was also notable when only high purity $\mathrm{N}_{2}$ was used in APPI operation, indicating that even a low concentration of oxygen is sufficient for the substitution reaction to take place efficiently. As reported earlier, even $1 \mathrm{ppm}$ of oxygen as an impurity is enough for substitution reactions to take place [13]. It is also possible that oxygen originates from solvent molecules that break down in the ion source, possibly catalyzed by the hot metal source block. This could explain the higher proportion of phenoxide ions in methanol than in acetonitrile. However, a significant proportion of substitution products was also observed in hexane, which does not support this theory (Figure 2). Oxygen could also enter the ion source dissolved in the solvents, which was tested by bubbling some of the solvents in helium flow while they were ultrasonicated prior to analysis. However, no difference was observed in the proportion of the phenoxide ions in the spectra. The effect of the dopant was also studied by changing its proportion, but it had no effect on the amount of substitution products. Finally, the possibility that the substitution products resulted from electrical discharge was studied by changing the distance between the APPI source block and the curtain plate, but the effect on the proportion of the substitution products was not significant.

\section{APPI versus APCI}

Finally, the performances of APPI and APCI for the studied compounds in hexane, methanol, and acetonitrile were compared. The ions formed in APCI were mainly the same as in APPI-the acidic compounds formed $[\mathrm{M}-\mathrm{H}]^{-}$, compounds of high EA formed $\mathrm{M}^{-}$, except hexachlorobenzene, which formed $[\mathrm{M}-\mathrm{Cl}+$ $\mathrm{O}^{-}$just as in APPI. However, the relative abundances of substitution products with 1,4-dinitrobenzene and 1,4-naphthoquinone were significantly lower in APCI than in APPI (Tables 5 and 6).

The ionization efficiency was significantly greater in APPI for the acidic compounds ionized by proton transfer and somewhat higher for the compounds of 
positive EA, ionized by electron capture, charge exchange, or substitution reaction (Figure 3). The reasons for these observations may be the sum of several factors and cannot be specified with the present experimental data.

The use of the dopant in APCI was also studied. The dopant, toluene, was introduced to the APCI heated nebulizer probe in the same way as to APPI-through a T-piece [1]. The analytes were analyzed by using hexane as the solvent. The sensitivity with dopant assisted APCI was just the same as without the dopant and a lot lower than with APPI. This indicates that the sensitivity in APCI cannot be improved by addition of dopant due to different ionization processes in APPI and APCI. In our APPI system the dopant is needed to initiate the whole ionization process, whereas in APCI the ionization process is initiated by the gas and solvent molecules and thus the dopant is not needed. This leads to differences in reactant ion composition in APPI and $\mathrm{APCI}$ and thus to differences in ionization efficiencies.

\section{Conclusions}

The negative ion APPI was studied by analyzing seven different compounds in 17 different solvent systems. The compounds of high gas-phase acidity were mostly ionized by proton transfer, whereas the compounds of positive EA formed $\mathrm{M}^{-\cdot}$ by electron capture or charge exchange of phenoxide ions by substitution reactions. Ionization of the analytes by proton transfer was suppressed when solvents that possess higher gas-phase acidities than the analytes were used. Solvents of high gas-phase acidity also suppressed the ionization efficiency for the compounds of positive EA, probably due to neutralization of $\mathrm{O}_{2}^{-}$, which results in the inhibition of charge exchange reaction between $\mathrm{O}_{2}^{-}$and the analytes. The ionization of all the analytes was blocked in halogenated solvents that possess positive EA. The phenoxide ions observed in the spectra of analytes of positive EA were probably formed in substitution reactions with $\mathrm{O}_{2}^{-}$.

The comparison between APPI and APCI showed that at least for the studied compounds better sensitivity can be achived by using APPI. The formation of somewhat different ions by the two ion sources indicates that the ionization processes in APPI and APCI are different. The introduction of dopant into APCI source did not overcome the differences between APCI and APPI spectra, nor did it improve the sensitivity of APCI.

\section{Acknowledgments}

This study was financially supported by the Finnish National Technology Center, Orion Pharma, Juvantia Pharma Ltd., and United Laboratories Ltd. Financial support for the construction of the APPI ion source was provided by Applied Biosystems. The authors gratefully acknowledge the assistance of Kati Hakala.

\section{References}

1. Robb, D. B.; Covey, T. R.; Bruins, A. P. Anal. Chem. 2000, 72, 3653-3659.

2. Syage, J. A.; Evans, M. D. Spectroscopy. 2001, 16, 14-21.

3. Rauha, J.-P.; Vuorela, H.; Kostiainen, R. J. Mass Spectrom. 2001, $36,1269-1280$.

4. Leinonen, A.; Kuuranne, T.; Kostiainen, R. J. Mass Spectrom. 2002, 37, 693-698.

5. Keski-Hynnilä, H.; Kurkela, M.; Elovaara, E.; Antonio, L.; Magdalou, J.; Luukkanen, L.; Taskinen, J.; Kostiainen, R. Anal. Chem. 2002, 74, 3449-3457.

6. Yang, C.; Henion, J. J. Chromatogr. 2002, 970, 155-165.

7. Kauppila, T.; Kuuranne, T. Meurer, E., C.; Eberlin, M. N.; Kotiaho, T.; Kostiainen, R. Anal. Chem. 2002, 74, 5470-5479.

8. Kertesz, V.; Van Berkel, G. J. J. Am. Soc. Mass Spectrom. 2002, 13, 109-117.

9. Koster, G.; Bruins, A. P. Mechanisms for Ion Formation in LC/MS by Atmospheric Pressure Photo-Ionization (APPI). Proceedings of the 49th ASMS Conference on Mass Spectrometry and Allied Topics; Chicago, IL, May, 2001.

10. Linstrom, P. J.; Mallard, W. G., Eds., NIST Chemistry WebBook, NIST Standard Reference Database Number 69, July 2001, National Institute of Standards and Technology, Gaithersburg MD, 20899 (http:/ / webbook.nist.gov).

11. Horning, E. C.; Carroll, D. I.; Dzidic, I.; Lin, R.; Stillwell, R. N.; Thenot, J.-P. J. Chromatogr. 1977, 142, 481-495.

12. Budzikiewicz, H. Mass Spectrom. Rev. 1986, 5(4), 345-380.

13. Dzidic, I.; Carroll, D. I.; Stillwell, R. N.; Horning, E. C. Anal. Chem. 1975, 47, 1308-1312. 